\title{
Adaptando materiais didáticos do ensino presencial para o ensino remoto
}

\author{
Adapting courseware from classroom teaching to remote teaching
}

Adaptación de materiales didácticos de la enseñanza presencial a la enseñanza remota

Bruna Ferreira Gugliano; Ricardo Lemos Sainz ${ }^{2}$

\section{RESUMO}

A crise gerada pela pandemia de COVID-19 forçou a adesão das instituições de ensino ao ensino remoto nãopresencial como uma alternativa para dar continuidade ao ano letivo, o que revelou diversas barreiras, entre elas a adaptação, por parte de docentes, do material didático para esta modalidade digital. Este artigo apresenta, a partir de uma revisão bibliográfica com abordagem qualitativa, levantamento de dados a respeito da produção de material didático para o ensino através das redes, com o objetivo de identificar algumas formas com que os materiais didáticos desenvolvidos para o ensino presencial podem ser adaptados para o ensino remoto não-presencial. Para isso, foi realizada uma pesquisa no banco de dados Google Scholar buscando artigos, capítulos de livros e recomendações combinando as palavras-chave "material didático" \& "educação a distância" e "material didático" \& "ensino remoto". A partir dessa busca, foram selecionadas e analisadas as referências que tratavam especificamente das características desses materiais para, por fim, apresentar recomendações para a produção de material didático para o ensino remoto, no formato de um infográfico.

Palavras-chave: Material didático; Ensino remoto não-presencial; Infográfico.

\begin{abstract}
The crisis generated by the COVID-19 pandemic forced the adherence of educational institutions to remote learning as an alternative to continue the school year, which revealed several barriers, including the adaptation, by teachers, of the courseware for this digital modality. This paper presents, based on a bibliographic review with a qualitative approach, data collection regarding distance learning courseware development, in order to identify some ways in which the didactic materials developed for classroom teaching can be adapted for remote, non-classroom teaching. To accomplish this goal, a search was carried out in the Google Scholar database looking for papers, book chapters and recommendations combining the keywords "teaching material" \& "distance education" and "teaching material" \& "remote education". From this search, references that specifically dealt with the characteristics of these materials were selected and analyzed to, finally, present recommendations for the production courseware for remote education, in the form of an infographic.
\end{abstract}

Keywords: Courseware; Remote learning; Infographic.

\footnotetext{
${ }^{1}$ Doutoranda em Design pelo Programa de Pós-Graduação em Design com ênfase em Tecnologia da Universidade Federal do Rio Grande do Sul (UFRGS), Porto Alegre/RS - Brasil. E-mail: brunafgugliano@gmail.com

${ }^{2}$ Doutor em Ciência e Tecnologia Agroindustrial e Professor Titular do Instituto Federal Sul-rio-grandense (IFSul) - Campus Pelotas, Pelotas/RS - Brasil. E-mail: ricardosainz@ifsul.edu.br
} 


\section{RESUMEN}

La crisis generada por la pandemia COVID-19 obligó a la adherencia de las instituciones educativas a la enseñanza remota de emergencia, como alternativa para continuar el curso escolar, lo que reveló varias barreras, entre ellas la adaptación, por parte de los docentes, del material didáctico para esta modalidad digital. Este artículo presenta, a partir de una revisión bibliográfica con enfoque cualitativo, la recolección de datos sobre la producción de material didáctico para la educación a distancia, con el fin de identificar algunas formas en las que los materiales didácticos desarrollados para la enseñanza presencial pueden ser adaptados para la enseñanza remota. Para ello, se realizó una búsqueda en la base de datos de Google Scholar buscando artículos, capítulos de libros y recomendaciones combinando las palabras clave "material didáctico" \& "educación a distancia" y "material didáctico" \& "enseñanza remota". A partir de esta búsqueda se seleccionaron y analizaron referencias que abordaron específicamente las características de estos materiales para, finalmente, presentar recomendaciones para la producción de material didáctico para la educación a distancia, en forma de uma infografía.

Palabras clave: Material didáctico; Enseñanza remota; Infografia.

\section{INTRODUÇÃO}

Em 26 de fevereiro de 2020, o primeiro caso de COVID-19 no Brasil foi confirmado (SANARMED, 2020). A partir desta data, diversas instituições de ensino, o que ocorreu em conformidade com outros países já afetados pela doença, suspenderam as atividades acadêmicas, gerando uma grande discussão quanto ao uso das tecnologias digitais para a manutenção do ensino, na modalidade remota. Barmpaliou (2020) chama a atenção para como a pandemia mundial de COVID-19 acentuou a dependência da sociedade quanto à infraestrutura digital, e como a crise forçou uma digitalização acelerada das instituições. Para Hintermann (2020), a pandemia gerou, em três meses, um avanço no uso das tecnologias digitais que antes levaria três anos.

O avanço "forçado" no uso das TDICs - Tecnologias Digitais de Informação e Comunicação - revelou a existência de algumas barreiras na utilização desses recursos por parte da comunidade escolar: docentes e discentes sobrecarregados, dificuldade no uso das tecnologias utilizadas e desigualdade no acesso às mesmas foram tópicos amplamente discutidos pela mídia e nos sites de redes sociais.

O uso das tecnologias digitais no Brasil é monitorado anualmente por diversas pesquisas; o Centro Regional de Estudos para o Desenvolvimento da Sociedade da Informação - CETIC, por exemplo, pesquisa o uso da internet e seus dispositivos em diversas perspectivas, como nos Domicílios, nas Empresas, nas Escolas, entre outros. Em 2019, 74\% dos brasileiros utilizaram a internet ao menos uma vez nos três meses anteriores à pesquisa. Há 10 anos atrás, esse percentual era de $41 \%$. Dos usuários frequentes, $99 \%$ utilizaram dispositivos móveis como celulares e tablets para fazer o acesso (AGÊNCIA BRASIL, 2020).

Ainda de acordo com o CETIC, durante a pandemia, 82\% dos usuários de internet com 16 anos ou mais que frequentam escola ou universidade acompanharam aulas ou atividades remotas. No entanto, cabe refletir: a presença e o uso frequente de dispositivos digitais significam, necessariamente, dominar essas tecnologias o suficiente para aprender com elas? Embora seja alta a porcentagem da população que está habituada a usar, principalmente, os sites e aplicativos de 
redes sociais, a aprendizagem remota exige uma capacidade de se autodirigir que nem sempre está desenvolvida (CARVALHO, 2013).

Uma das principais características da cultura digital é o acesso a uma quantidade infinita de informações; essa possibilidade torna as narrativas descontínuas, fragmentadas e em constante transformação (KENSKI, 2003). Além disso, a cultura de colaboração crescente da internet, que permite ao usuário ser, ao mesmo tempo, espectador e criador de conteúdo, torna a aprendizagem unilateral algo difícil de se manter. Para Don Tapscott (2009), as crianças e adolescentes que cresceram já na era digital tendem a querer participar mais no processo de ensino-aprendizagem, escolhendo o que aprendem, quando e como. Ou seja: são jovens que esperam ter uma conversa e opinar sobre os temas que estão sendo abordados em sala de aula. Desta forma, torna-se difícil, por exemplo, se manter atento muito tempo em um mesmo texto, vídeo ou até mesmo em uma aula por webconferência que não possua interação.

A partir dessa discussão e do vislumbre da inevitável adesão ao ensino remoto não-presencial em períodos de crise, esse trabalho se propõe a realizar um levantamento, através de pesquisa bibliográfica, de orientações para o desenvolvimento de material didático para o ensino através das redes, com o objetivo de identificar algumas formas com que os materiais didáticos desenvolvidos para o ensino presencial podem ser adaptados para o ensino remoto não-presencial.

O ensino remoto, principalmente durante a pandemia, ocorre de forma diferente da EaD. A Educação a Distância no Brasil possui legislação própria e tem seus cursos planejados já no formato a distância, com recursos e pessoal específico para seu desenvolvimento. Conforme Hodges et al. (2020), 0 objetivo do ensino remoto "não é recriar um sistema educacional robusto, mas fornecer acesso temporário a suportes e conteúdos educacionais de maneira rápida, fácil de configurar e confiável, durante uma emergência ou crise" (2020, p. 6). Desta forma, procurou-se, através desta revisão, auxiliar professoras e professores que, na ausência de uma equipe técnica para desenvolver os materiais, precisam de soluções alternativas para adaptar suas aulas.

A construção desse artigo deu-se a partir de uma revisão bibliográfica com abordagem qualitativa, levantando informações a respeito da produção de material didático para o ensino a distância em geral. Para isso, foi realizada uma pesquisa no banco de dados Google Scholar buscando artigos, capítulos de livros e recomendações combinando as palavras-chave "material didático" \& "educação a distância" e "material didático" \& "ensino remoto". A partir dessa busca, foram selecionadas as referências que tratavam especificamente das características desses materiais, como apresentado na revisão teórica a seguir. As recomendações contidas nos referenciais que tratavam especificamente de EaD foram adaptadas para a execução no ensino remoto não-presencial. Já as que tratavam de ensino remoto foram complementadas com sugestões de aplicação na prática. Por fim, as recomendações geradas foram apresentadas em um infográfico, organizando e resumindo os dados levantados.

\section{REVISÃO TEÓRICA}

Dado o caráter emergencial em que as instituições de ensino necessitaram se adaptar ao ensino remoto, diversas cartilhas e pesquisas foram publicadas com o intuito de auxiliar professoras e professores no desafio de ensinar através das tecnologias. Essas pesquisas possuem muitos vieses, áreas e metodologias, porém, parece haver um consenso entre muitas: não basta apenas inserir os 
recursos didáticos utilizados na sala de aula presencial para os Ambientes Virtuais de Aprendizagem; é necessária uma adaptação. Para Kuklinski e Cobo (2020), "a transição não é automática nem tem relação com utilizar mais tecnologias, e sim com um processo ambicioso capaz de integrar o tecnológico, o cognitivo, o relacional e o pedagógico".

Vieira et al (2020), através de questionário com estudantes que passaram por essa transição, constataram que "há a necessidade de um modelo mental diferente, tanto de alunos quanto de professores, pois o processo exige ainda mais do aluno, que precisa dedicar, muitas vezes, um tempo ainda maior para acessar os materiais e estudar, geralmente, sozinho" (p. 13). Este caráter autodirigido do ensino remoto implica na necessidade de um material didático de maior qualidade, considerando a ausência do professor de forma presencial no momento de estudo (MILL; SILVA; GONÇALVES, 2018).

Para que a base do processo de mediação seja efetivada no ensino-aprendizagem a distância, torna-se necessário um cuidado especial na elaboração dos materiais didáticos que funcionam como instrumentos que subsidiam o desenvolvimento de um curso ou programa na $\mathrm{EaD}$, pois estes desempenham um papel de extrema importância na condução da aprendizagem do aluno. (LIMA; SANTOS, 2019, p. 6).

De acordo com os "Referenciais de Qualidade para Educação Superior a Distância" (BRASIL, 2007), o material didático disponibilizado online deve:

- Ser construído em linguagem dialógica³, na forma de uma conversa entre docente e discente;

- Prever um Guia Geral do Curso, que oriente os estudantes sobre a estrutura do curso ou disciplina, os materiais didáticos que serão utilizados, as formas de avaliação e de interação, entre outros tópicos gerais e um Guia que oriente sobre a utilização dos materiais didáticos e um cronograma com atividades síncronas e avaliações;

- Detalhar o que se espera que os e as estudantes compreendam ao final da lição, de modo a que estes possam se auto avaliar;

- Indicar as referências utilizadas, possibilitando expandir a aprendizagem.

Além disso, os autores dos Referenciais recomendam que os materiais sejam testados e ajustados conforme as necessidades são percebidas. Lima e Santos (2019) também evidenciam a importância de fornecer uma visão global da temática da disciplina ou curso, tal como os Guias sugeridos pelos Referenciais (2017), mas também abordam a questão do design do material disponibilizado, que deve ser visualmente interessante, de forma a estimular a aprendizagem. A Figura 1 apresenta um exemplo de material didático no formato $p d f$, que apresenta, nas páginas iniciais, a ementa e os objetivos, conforme indicam os Referenciais (2017).

Com relação ao equilíbrio entre atividades síncronas e assíncronas, o documento "Primeiros passos para Ensino Remoto" (CECIERJ, 2020) salienta a importância de disponibilizar os materiais de aula para download, pois as e os estudantes podem ter dificuldades no carregamento de vídeos e arquivos em tempo real. O manual indica, ainda, parcimônia nas videoconferências, pois podem ser "muito

\footnotetext{
3 "A Linguagem Dialógica é a forma característica da comunicação utilizada na educação a distância, ela surge da união dos termos Linguagem, que é a capacidade humana de manifestar expressões de sentimentos, desejos, opiniões e troca de informações em diferentes culturas. Juntamente do termo Dialógica, que carrega em sua essência o significado de dialogismo, consistindo na construção e reflexão sob a forma de diálogo." IFSC. Disponível em: <https://moodle.ifsc.edu.br/mod/book/view.php?id=36093\&chapterid=2098>. Acesso em: 13 dez 2020.
} 
custosas não apenas pelos dados que consomem, mas também por se imporem como prioridade em um horário arbitrário. Não sabemos da realidade de cada um dos participantes do curso" (CECIER], 2020, p. 3).

\section{Figura 1 - Material didático apresentando Ementa e Objetivos}

\section{EMENTA:}

Ensino remoto. Competências e habilidades do professor. Princípios da aprendizagem. Design para oferta de conteúdo educacional no ensino remoto.

\section{OBJETIVOS:}

Geral

- Construir o design para oferta de conteúdo educacional no ensino remoto.

\section{Específicos}

- Compreender o significado de ensino remoto

- Identificar as competências e habilidades requisitadas do professor para essa prática.

Reconhecer os princípios de aprendizagem no ensino remoto.

Fonte: GARCIA et al, 2020, p. 4.

Além do peso de carregamento dos arquivos (downloade upload), é importante pensar na sobrecarga cognitiva que a disponibilização de uma quantidade excessiva de conteúdos pode causar nos estudantes. No microlearning, o conteúdo é dividido em várias unidades, desenvolvidas com linguagem acessível para uma rápida visualização (ROCHA; JOYE; MOREIRA, 2020). De acordo com Brasil, Lemos e Rosa Jr (2017), este modelo "se baseia em uma característica intrínseca do cérebro humano, que é a capacidade de manter a concentração durante curtos períodos de tempo com mais facilidade do que por períodos longos" (p. 7). O microlearning costuma ser utilizado em cursos autoinstrucionais e treinamentos corporativos para ensinar atividades de baixa complexidade, ou seja, pode ser utilizado para aulas introdutórias ou de definição de conceitos.

O tempo para realizar as atividades também deve ser considerado. Aquele momento reservado para assistir as aulas presenciais pode agora estar sendo dividido com tarefas domésticas, realizado em espaços inadequados para o estudo e com equipamentos compartilhados com outros moradores da casa. Filatro (2018), sugere que sejam fornecidos templates, ou seja, modelos para as entregas das atividades (por exemplo, um arquivo em .docx já com a formatação esperada), de forma a auxiliar estudantes quanto aos tópicos que devem ser contemplados e a formatação esperada, diminuindo o tempo necessário para a sua realização (figura 2). 


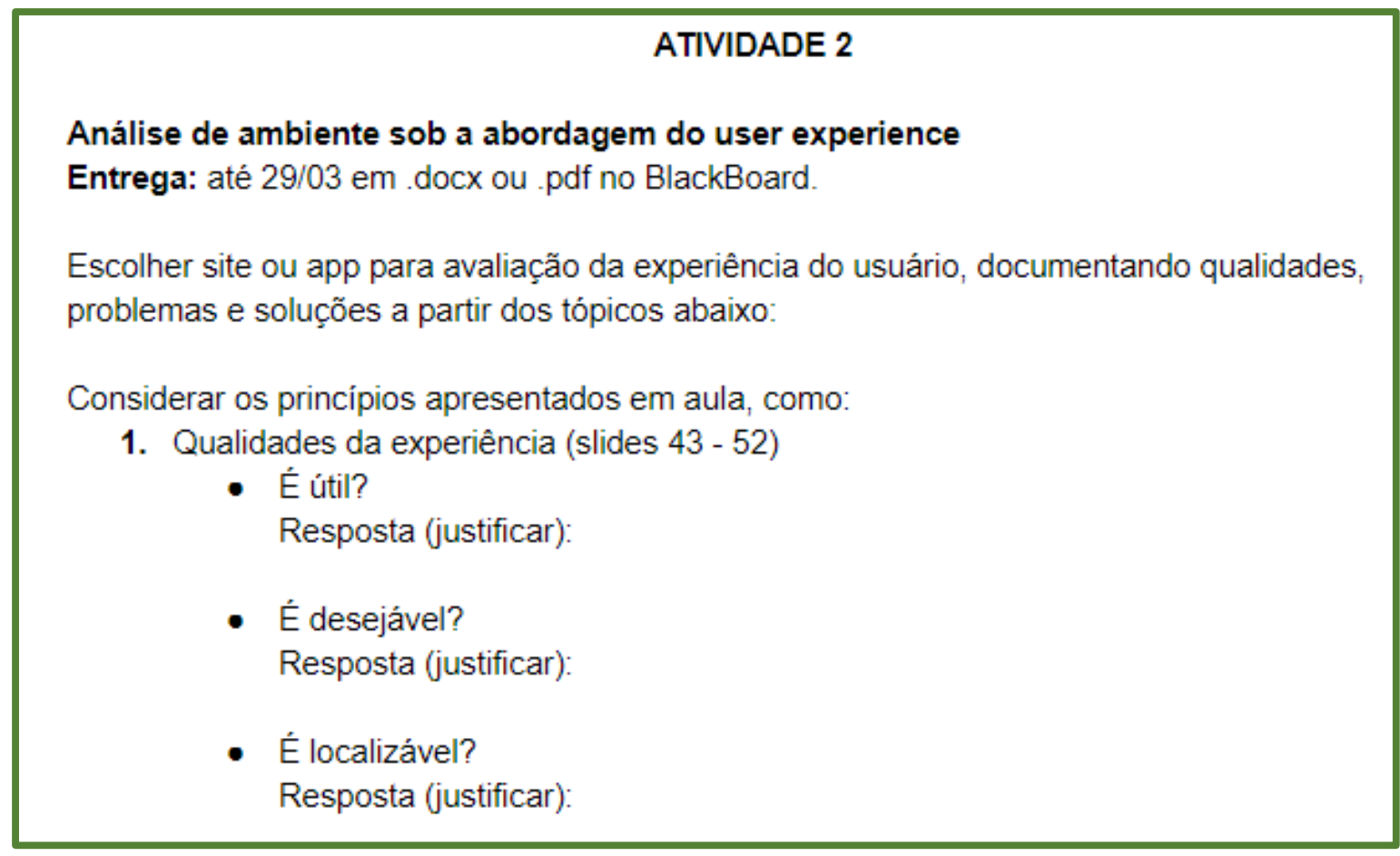

Fonte: a autora.

Ainda conforme Filatro (2018), o uso de várias mídias pode ser feito para atender a diferentes necessidades de aprendizagem, como:

- Processamento de informações: mídia impressa, hipertexto (site na web) e livros digitais.

- Articulação entre teoria e prática: tutoriais multimídias, objetos de aprendizagem e screencasts.

- Discussão e argumentação: apresentação de slides, animações e podcasts.

- Modelagem de comportamento: ilustrações multiquadros, podcasts e vídeos.

- Prática profissional: estudos de caso, animações, infográficos e simulações.

Da mesma forma, Kuklinski e Cobo (2020) sugerem que as aulas possuam uma narrativa transmídia, ou seja, que os conteúdos sejam divididos e partilhados através de diferentes mídias. Em um cenário ideal, essas mídias, por exemplo, vídeos, textos, podcasts, infográficos, entre outros, poderiam ser produzidas pelos próprios docentes. No entanto, considerando o momento de crise sanitária, os autores sugerem o que chamaram de "ensino remoto adaptado", que abrangeria não uma nova produção, mas um ajuste e curadoria dos materiais didáticos já existentes, além da disponibilização dos materiais mais densos com comentários e/ou resenhas feitas por docentes. Essa estratégia abrangeria tanto sincronia quanto assincronia, equilibrando mais perfis de estudantes (os mais ativos e os mais passivos).

Quanto à linguagem utilizada, Hack (2011) retoma a questão da linguagem dialógica, porém adverte quanto ao uso de uma linguagem infantilizada; para o autor, o importante é envolver discentes no diálogo, de forma que esses se sintam capazes de complementar os conteúdos com suas próprias 
ideias, fazendo questões e se dirigindo ao aluno por "você". Além disso, pensando na autonomia dos aprendizes, o autor indica a importância de inserir links com informações adicionais e exemplos dos conteúdos abordados.

Para Clark e Mayer (2016), usar outras linguagens além da textual auxilia na aprendizagem ao permitir que educandos façam conexões entre as mídias, por exemplo, entre a figura apresentada e o texto explicativo, organizando mentalmente as informações. No entanto, é importante destacar que as figuras utilizadas não devem ser meramente ilustrativas, e sim relevantes para acrescentar significado ao conteúdo apresentado (TORREZZAN; BEHAR, 2009). A partir dessas acepções, podese concluir que não há a necessidade de os docentes buscarem figuras para "decorar" os materiais, a menos que sejam essenciais para a aprendizagem. A intenção é manter os materiais agradáveis de serem acessados, de forma que a apresentação das aulas seja "tão ou mais atrativa do que aquilo que aluno encontrar disponível na rede de comunicação aberta" (GARCIA et al, 2020. p. 13).

\section{RESULTADOS}

A partir das recomendações elencadas na revisão teórica foi possível criar um infográfico resumindo e organizando o conteúdo pesquisado, de forma a propor recomendações, no contexto do ensino remoto, para a adaptação ou desenvolvimento dos materiais didáticos pelos docentes, sem o apoio de uma equipe técnica multidisciplinar.

O infográfico foi desenvolvido a partir das informações do Quadro 1, que resume os dados levantados nesta pesquisa e adiciona algumas considerações (na coluna "Como pode ser feito?"), conforme apresentado abaixo.

Quadro 1 - Recomendações de adaptações

\begin{tabular}{|l|l|l|}
\hline \multicolumn{1}{|c|}{ Fonte } & Recomendação sobre o material & \multicolumn{1}{c|}{ Como pode ser feito? } \\
\hline $\begin{array}{l}\text { Referenciais de Qualidade } \\
\text { para Educação Superior a } \\
\text { Distância (BRASIL, 2007) }\end{array}$ & $\begin{array}{l}\text { Ser construído em linguagem } \\
\text { dialógica. }\end{array}$ & $\begin{array}{l}\text { Escrever como se fosse um } \\
\text { roteiro, contendo as "falas" que } \\
\text { seriam ditas em sala de aula. }\end{array}$ \\
\hline $\begin{array}{l}\text { Referenciais de Qualidade } \\
\text { para Educação Superior a } \\
\text { Distância (BRASIL, 2007) }\end{array}$ & $\begin{array}{l}\text { estrutura do curso ou disciplina, os } \\
\text { materiais didáticos que serão } \\
\text { utilizados, as formas de avaliação e de } \\
\text { interação, entre outros tópicos gerais } \\
\text { e um Guia que oriente sobre a } \\
\text { utilização dos materiais didáticos e um } \\
\text { cronograma com atividades síncronas } \\
\text { e avaliações. }\end{array}$ & $\begin{array}{l}\text { Gravar um vídeo de apresentação } \\
\text { explicando como se darão as } \\
\text { resumindo essas informações e } \\
\text { disponibilizá-lo junto ao vídeo. }\end{array}$ \\
\hline $\begin{array}{l}\text { Referenciais de Qualidade } \\
\text { para Educação Superior a } \\
\text { Distância (BRASIL, 2007) }\end{array}$ & $\begin{array}{l}\text { Testar e ajustar conforme as } \\
\text { necessidades são percebidas. }\end{array}$ & $\begin{array}{l}\text { Criar uma página colaborativa } \\
\text { (ex.: Google Docs) em que os } \\
\text { alunos possam escrever possíveis } \\
\text { erros percebidos no material. }\end{array}$ \\
\hline $\begin{array}{l}\text { Referenciais de Qualidade } \\
\text { para Educação Superior a } \\
\text { Distância (BRASIL, 2007) }\end{array}$ & $\begin{array}{l}\text { Indicar as referências utilizadas, } \\
\text { possibilitando expandir a } \\
\text { aprendizagem. }\end{array}$ & $\begin{array}{l}\text { Criar uma pasta compartilhada } \\
\text { contendo os materiais utilizados; } \\
\text { indicar títulos e links no mesmo } \\
\text { espaço onde estão as aulas. }\end{array}$ \\
\hline
\end{tabular}

\footnotetext{
${ }^{4}$ Considerando a efemeridade dos conteúdos publicados na internet, é importante sempre revisitar os links indicados, a fim de verificar se ainda estão "no ar".
} 


\begin{tabular}{|c|c|c|}
\hline $\begin{array}{l}\text { Primeiros passos para Ensino } \\
\text { Remoto (CECIERJ, 2020) }\end{array}$ & $\begin{array}{l}\text { Basear a aula em leituras e discussões } \\
\text { de texto. }\end{array}$ & $\begin{array}{l}\text { Disponibilizar mais de um texto } \\
\text { sobre o mesmo tema, distribuir } \\
\text { entre os alunos e pedir para os } \\
\text { grupos que leram o mesmo texto } \\
\text { realizarem uma síntese de suas } \\
\text { anotações. Utilizar ferramentas } \\
\text { que permitam o } \\
\text { acompanhamento (ex.: Google } \\
\text { Docs ou Fórum do AVA). }\end{array}$ \\
\hline $\begin{array}{l}\text { Primeiros passos para Ensino } \\
\text { Remoto (CECIERJ, 2020) }\end{array}$ & $\begin{array}{l}\text { Disponibilizar os materiais de aula } \\
\text { para download. }\end{array}$ & $\begin{array}{l}\text { Utilizar ambientes compartilhados } \\
\text { (ex.: Google Drive, Moodle, } \\
\text { Dropbox) com os materiais, } \\
\text { inclusive as videoaulas. }\end{array}$ \\
\hline $\begin{array}{l}\text { Primeiros passos para Ensino } \\
\text { Remoto (CECIERJ, 2020) }\end{array}$ & Parcimônia nas videoconferências. & $\begin{array}{l}\text { Fazer um cronograma de } \\
\text { videoconferências com horário de } \\
\text { início e de fim para cada } \\
\text { participante. }\end{array}$ \\
\hline $\begin{array}{l}\text { Brasil, Lemos e Rosa Jr } \\
\text { (2017) } \\
\text { Rocha, Joye e Moreira } \\
(2020)\end{array}$ & Utilizar estratégias do microlearning. & $\begin{array}{l}\text { Dividir os materiais (textos, } \\
\text { apresentações de slides, etc.) em } \\
\text { unidades menores. }\end{array}$ \\
\hline Filatro (2018) & Fornecer templates para as atividades. & $\begin{array}{l}\text { Criar documentos (.doc, .docx., } \\
\text { google docs) com uma } \\
\text { formatação padrão (ABNT, por } \\
\text { exemplo) com a descrição da } \\
\text { atividade e o espaço para } \\
\text { preenchimento. }\end{array}$ \\
\hline $\begin{array}{l}\text { Filatro (2018) } \\
\text { Hack (2011) } \\
\text { Kuklinski e Cobo (2020) }\end{array}$ & $\begin{array}{l}\text { Utilizar diversas mídias para abordar } \\
\text { os conteúdos. }\end{array}$ & $\begin{array}{l}\text { Fazer uma curadoria dos } \\
\text { materiais encontrados na web } \\
\text { sobre os temas de aula e } \\
\text { disponibilizar para os alunos, } \\
\text { contextualizando e fazendo } \\
\text { comentários. }\end{array}$ \\
\hline $\begin{array}{l}\text { Clark e Mayer (2016) } \\
\text { Garcia et al (2020) } \\
\text { Torrezzan; Behar (2009) }\end{array}$ & $\begin{array}{l}\text { Usar figuras que complementem o } \\
\text { texto. }\end{array}$ & $\begin{array}{l}\text { Buscar ou produzir gráficos, } \\
\text { esquemas, fluxogramas e } \\
\text { infográficos que complementem e } \\
\text { sintetizem os conceitos } \\
\text { abordados. }\end{array}$ \\
\hline
\end{tabular}

Fonte: autoria própria.

Para facilitar a leitura, as informações apresentadas no infográfico foram divididas em quatro categorias:

1. sobre a linguagem utilizada, que aborda os textos criados;

2. sobre a organização do conteúdo, que trata das mídias que podem ser desenvolvidas e como organizá-las;

3. sobre a realização de atividades, que sugere alguns procedimentos a serem tomados ao aplicar e realizar atividades e

4. sobre a apresentação do conteúdo, que aborda a forma como apresentam-se visualmente os materiais elaborados e/ou adaptados.

O resultado encontra-se na figura 3, abaixo. 
Figura 3 - Recomendações para a produção de material para o ensino remoto

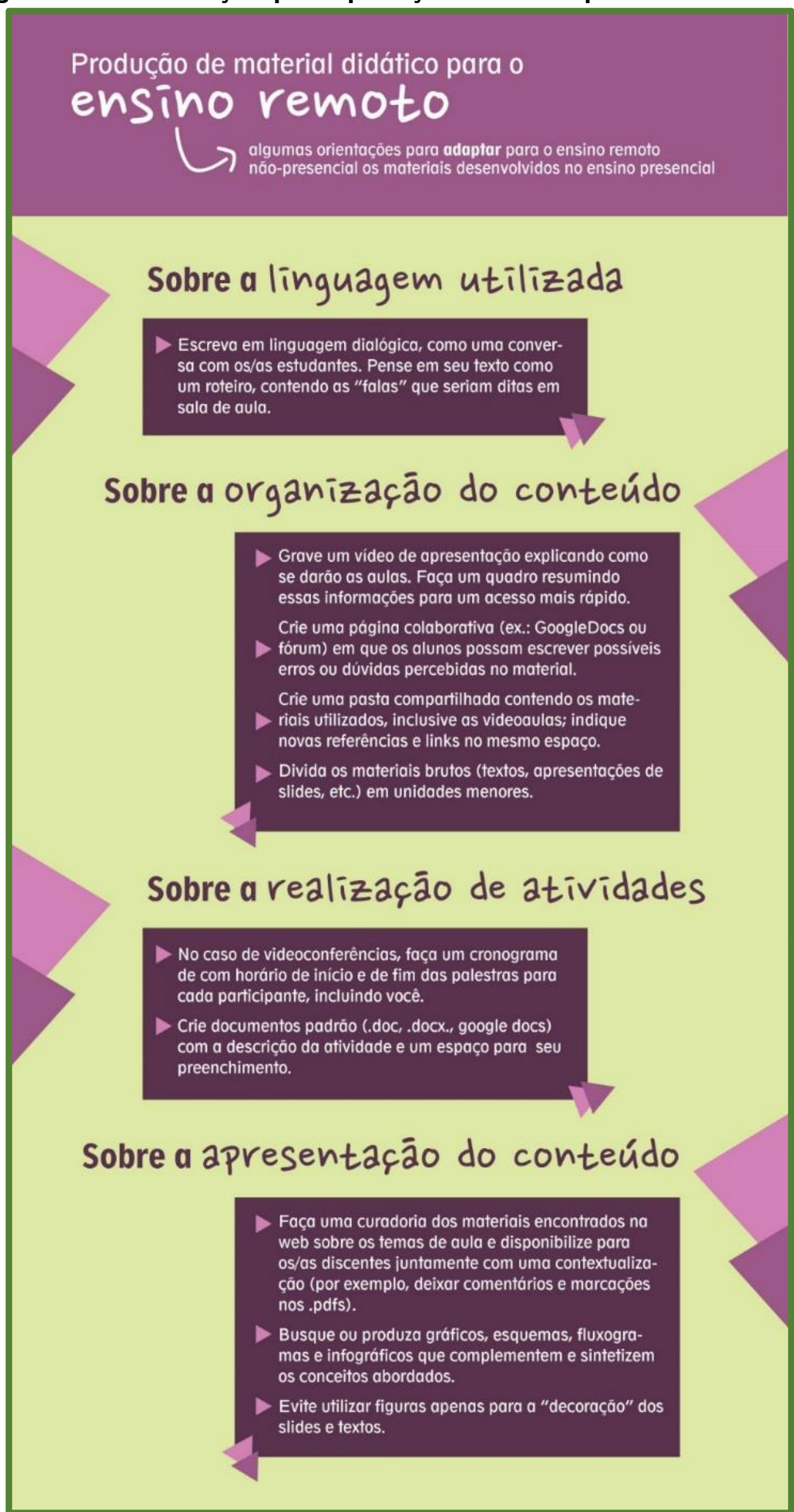

Fonte: autoria própria. 


\section{CONSIDERAÇÕES FINAIS}

A emergência do ensino remoto não-presencial na pandemia de Covid-19 trouxe à tona as dificuldades em lidar e acessar as tecnologias digitais por parte dos membros da comunidade escolar. Neste contexto, percebe-se a importância de compartilhar experiências e conhecimentos que estão sendo produzidos neste período, a fim de, em um esforço coletivo, facilitar o desenvolvimento das atividades a distância. Joye et al (2018) afirmam a importância dos professores e professoras receberem formação para serem autores de seus próprios materiais didáticos, pois estes possuem o conhecimento da realidade e necessidade de seus estudantes.

Com o intuito de dar suporte aos docentes neste período de crise, este artigo procurou organizar e apresentar algumas orientações em relação à produção dos materiais didáticos, utilizando, após a realização da revisão, os conhecimentos da formação da autora em Design para criar um produto que informasse, de forma lúdica, os possíveis passos a serem dados pelos docentes que desejam adaptar seus materiais. Desta forma, considera-se cumprido o objetivo de identificar as formas com que os materiais didáticos desenvolvidos para o ensino presencial podem ser adaptados para o ensino remoto não-presencial. Para estudos futuros, se sugere uma pesquisa com docentes e discentes que tiveram a experiência do ensino remoto, a fim de levantar, junto a estas e estes, novas recomendações para o desenvolvimento dos materiais didáticos.

\section{REFERÊNCIAS}

BARMPALIOU, Nayia. Amenazas emergentes en ciberseguridad: implicaciones para América Latina y el Caribe. 2020. In: BANCO INTERAMERICANO DE DESAROLLO. Ciberseguridad: riesgos, avances y el camino a seguir en America Latina y el Caribe. 2020. Disponível em: https://publications.iadb.org/publications/spanish/document/Reporte-Ciberseguridad-2020-riesgosavances-y-el-camino-a-seguir-en-America-Latina-y-el-Caribe.pdf. Acesso em: 08 nov 2020.

BRASIL. Referenciais de Qualidade para Educação Superior a Distância. 2007. Disponível em: http://portal.mec.gov.br/seed/arquivos/pdf/legislacao/refead1.pdf. Acesso em: 19 out 2020.

BRASIL, Lina Sandra Barreto; LEMOS, Alysson Feliciano; ROSA JR., Onivaldo. Microlearning, recomendação de estudos e rede social em curso autoinstrucional: a inovação no desenho da oferta do programa educacional modular de manejo da tuberculose na atenção básica. 2017.

https://ares.unasus.gov.br/acervo/html/ARES/10586/1/MICROLEARNING\%2C\%20RECOMENDA\%C 3\%87\%C3\%830_Cap3.pdf. Acesso em: $18 \mathrm{dez} 2020$

CAROLEI, Paula. Processo de criação de hipertextos e atividades. In: KENSKI, Vani (org.) Design Instrucional para Cursos Online. São Paulo: Artesanato Educacional, 2019.

CARVALHO, Marie Jane Soares. 2013. Proposições e controvérsias no conectivismo. Revista Iberoamericana de Educación a Distancia, volume 16, no 2, p. 09-31.

CECIERJ. Primeiros passos para Ensino Remoto. 2020. Disponível em: https://canal.cecierj.edu.br/recurso/17375. Acesso em: 16 dez 2020.

CLARK, Ruth C.; MAYER, Richard E. E-learning and the science of instruction: Proven guidelines for consumers and designers of multimedia learning. John Wiley \& Sons, 2016.

FILATRO, Andrea. Como preparar conteúdos para EAD. Saraiva Educação SA, 2018. 
GARCIA, Tânia Cristina Meira et al. Ensino remoto emergencial: proposta de design para organização de aulas. Natal: SEDIS/UFRN, 2020.

HACK, Josias Ricardo. Introdução à educação a distância. Florianópolis: LLV/CCE/UFSC, 2011.

HINTERMANN, Francis. 2020. 3 Powerful Ways the Pandemic Is Changing Research Forever. Disponível em: https://www.accenture.com/us-en/blogs/accenture-research/3-powerful-ways-thepandemic-is-changing-research-forever. Acesso em: 08 nov 2020.

HODGES, Charles et al. As diferenças entre o aprendizado online e o ensino remoto de emergência. Revista da Escola, Professor, Educação e Tecnologia, v. 2, 2020.

JOYE, Cassandra Ribeiro et al. MATERIAL DIDÁTICO PARA A EAD: AUTORIA E CRIATIVIDADE. EmRede-Revista de Educação a Distância, v. 5, n. 1, p. 149-166, 2018.

KENSKI, Vani Moreira. Tecnologias e ensino presencial e a distância. Papirus Editora, 2013.

KUKLINSKI, H. P.; COBO, Cristóbal. Expandir la universidad más allá de la enseñanza remota de emergência: ideas hacia un modelo híbrido post-pandemia. 2020. Disponível em: https://outliersschool.net/wp-content/uploads/2020/05/Expandir_la_universidad.pdf. Acesso em: 16 dez 2020.

LIMA, Artemilson; SANTOS, Simone. 0 material didático na EAD: Princípios e processos. 2019. Disponível em: https://ead.ifrn.edu.br/portal/wpcontent/uploads/2017/07/Producao_de_Material_Didatico_Curso_de_Gestao_EaD.pdf. Acesso em: 12 dez 2020.

MILL, Daniel; SILVA, Aparecida Ribeiro da; GONÇALVES, Maria Ribeiro. Material didáticos para educação a distância. 2018. In: MILL, Daniel et al. (ed.). Dicionário crítico de educação e tecnologias e de educação a distância. UFSCar, 2018.

ROCHA, Sinara Socorro Duarte; JOYE, Cassandra Ribeiro; MOREIRA, Marília Maia. A educação a distância na era digital: tipologia, variações, uso e possibilidades da educação online. Research, Society and Development, v. 9, n. 6, p. e10963390-e10963390, 2020.

SANARMED. Linha do tempo do Coronavirus no Brasil. 2020. Disponível em: https://www.sanarmed.com/linha-do-tempo-do-coronavirus-no-brasil. Acesso em: 06 nov 2020.

TAPSCOTT, Don. Grown up digital. Boston: McGraw-Hill Education, 2009.

TORREZZAN, C. A. W.; BEHAR, P. A. Parâmetros para a construção de materiais educacionais digitais do ponto de vista do design pedagógico. In: BEHAR, Patricia (Org.). Modelos Pedagógicos em Educação a Distância. São Paulo: Artmed, 2009.

VIEIRA, K. M. et al.Vida de Estudante Durante a Pandemia: Isolamento Social, Ensino Remoto e Satisfação com a Vida. EaD em Foco, v. 10, n. 3, e1147, 2020. 